\title{
Simultaneous transmission of adenocarcinoma after kidney transplantation. Report of two rare cases
}

\author{
Transmissão simultânea de adenocarcinoma após transplante renal. \\ Relato de 2 casos raros \\ Pedro Exman', Sibele Inacio Meireles², Renata Couldry², Elias David Neto³, Jorge Sabbaga ${ }^{1}$
}

\begin{abstract}
Malignancy related to donor after transplantation is a very rare situation that can be classified in two categories. The first is donor cell derived malignancy and the second, most rare, is tumor transmission which include the development of malignancy in a misdiagnosed donor pre-existent solid organ. This condition has good prognosis mainly because of recipient immune response, and patients are treated with explatantion of the graft associated with immunotherapy withdraw. Accordingly, we report two cases of female patients that have received their kidneys and tumors transplanted from the same male donor which DNA analysis confirm the same donor origin. Both patients were treated with the same therapy but different disease presentation.
\end{abstract}

Keywords: Adenocarcinoma; Transplantation; Transmission; Neoplasms/immunology

\begin{abstract}
RESUMO
Neoplasia associada ao transplante de orgãos é uma situacão extremamente rara que pode ser classificada em 2 duas categorias. A primeira quando o tumor se desenvolve da célula do doador após a realização do transplante, e a segunda, mais rara, é a transmissão para o receptor de tumores metastáticos pré-existentes e não diagnosticados do doador. Apesar de rara, esta situação apresenta um bom prognóstico e os pacientes são tratados com a retirada do enxerto e a suspensão da imunossupressão. Neste artigo, relatamos 2 mulheres que foram diagnosticadas com tumores transmitidos pelo mesmo doador do sexo masculino após serem submetidas a transplantes renais, com confirmação da mesma origem tumoral por análise de DNA.
\end{abstract}

Descritores: Adenocarcinoma; Transplante; Transmissão; Neoplasias/imunologia

1. Instituto do Cancer do Estado de São Paulo, São Paulo, SP, Brazil.

2. Hospital Sírio-Libanês, São Paulo, SP, Brazil.

3. Hospital das Clínicas, Faculdade de Medicina, Universidade de São Paulo, São Paulo, SP, Brazil.

Conflicts of interest: The authors declare that they have no competing interests.

Corresponding author: Pedro Exman

E-mail: pedroexman@hotmail.com

Received on: February 1, 2017 | Accepted on: September 6, 2017

DOI: 1026790/BJO20171345A34 


\section{INTRODUCTION}

Although rare, malignancy after solid organ transplantation may occur by three different ways. The appearance of new tumor in the recipient (de-novo tumors) is the first and most common one and usually involves a viral induced neoplasm. Epstein-Bar virus (EBV) related lymphomas are the prototype of this condition, caused by the impairment in the clearance of viral agents due to immunosuppression. The second way is directly related to immunosuppression and loss of immunological surveillance in pre-existing premalignant lesions and, more rarely, the ones that recur from preexisting tumors. Both first and second mechanism, naive cancer cells are originated from the recipient patient. ${ }^{11,2)}$ Donor related transplant malignancy, the third mechanism, is a very rare condition and can be further classified in two different categories: donor cell derived malignancy and tumor transmission, which includes the development of tumors in recipients due to transmission of a donor pre-existent solid organ tumor, often misdiagnosed at the time of transplantation. Because of its allotransmission nature, graft-related malignancy has better prognosis and its treatment is based on interruption of the immunosuppressive therapy and concurrent explantation of the graft, with chemotherapy been very rarely necessary. ${ }^{(1,2)}$

In this article we report we report two cases of female patients that have received their kidneys and tumors transplanted from the same male donor. Donor origin of the tumors was confirmed by DNA analysis.

\section{Case Reports}

Patient A

A 23-year-old caucasian female, with no personal or familiar medical history, was admitted with signs and symptoms of renal failure. Initial laboratory tests showed serum creatinine and blood urea nitrogen (BUN) of $18 \mathrm{mg} / \mathrm{dL}$ and $642 \mathrm{mg} / \mathrm{dL}$, respectively. Renal ultrasound demonstrated bilateral renal atrophy. Renal failure etiology has not been clarified even with kidney biopsy and patient progressed to a dialysis dependency. After two years, patient underwent to kidney transplantation from cadaver donor with no surgical complications. No macroscopically kidney anomaly was noted during the surgery and time zero biopsy showed acute glomerulonephritis, a common find in the renal graft before the transplant. There were no postoperative complications and the patient was discharged after 18 days, using tacrolimus, prednisone and mycophenolate mofetil. Five months after transplantation, patient was found to be uremic again with no changes in imaging tests. Graft biopsy showed preserved glomeruli with normal cellularity as well as normal mesangial matrix. However, it surprisingly showed metastatic adenocarcinoma infiltrating renal interstitium. Immunohistochemical tests showed positivity for CA19.9, CK7, CK20, and negativity for CDX-2, TTF-1 and PSA, suggesting gastrointestinal metastatic adenocarcinoma although no evident primary lesion after complete investigation.

PET-CT scan demonstrated a low to moderate uptake in supraclavicular and retroperitoneal nodes (SUVmax 3.5), and a fine needle biopsy confirmed metastatic carcinoma. Liver and lungs had no signs of metastatic disease and no serum tumor markers were increased. Patient underwent to transplantectomy and no superficial alteration was seen in the graft. After removal, whole kidney was sent to pathological analysis (Figure 1) that confirmed a poorly differentiated, mucinous adenocarcinoma with signet ring cells, infiltrating the renal parenchyma. Any other oncologic treatment was offered, but transplantectomy and withdrawal of immunosuppressive agents. Since then, the patient did not manifest any disease symptoms and has experienced gradual reduction of nodal metastatic lesions. Patient is currently without disease evidence, completing 1 year of follow up.
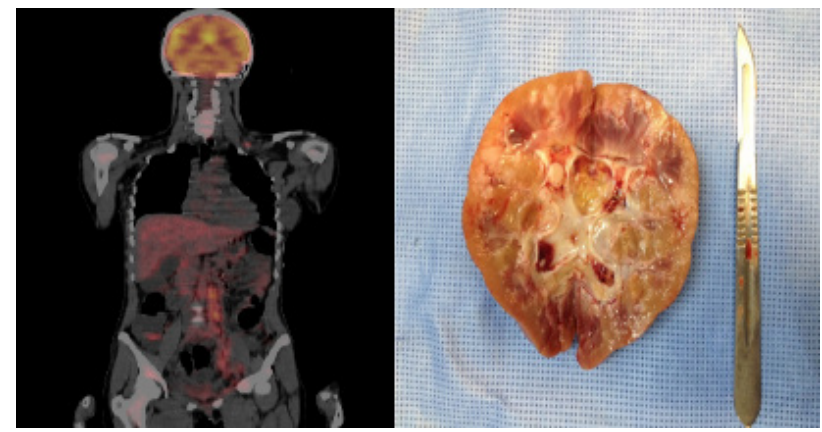

Figure 1. Transmitted tumor seen in surgical specimen and its node metastasis in PET-CT. 
A) PET-CT of patient A showing a low to moderate uptake in left supraclavicular and retroperitoneal nodes (SUVmax 3.5), which fine needle biopsy confirmed metastatic carcinoma. B) Surgical specimen showing tumor implantation in the renal parenchyma.

\section{Patient B}

A 54-year-old caucasian female with polycystic kidney disease, developed chronic renal failure and initiated on a chronic dialysis program when her creatinine clearance reached of $4.65 \mathrm{~mL} / \mathrm{min}$. Her medical history also included hypertension, hypercholesterolemia and coronary artery insufficiency. After three years of hemodialysis, she successfully underwent to a renal transplantation derived by same cadaver donor of case A. Like the other patient, her transplant procedure was also performed with no complications. Similarly, no macroscopic kidney anomaly was noted during the surgery. There was no complication in the post-operative period and she was discharged on day 13 post transplantation. She was also maintained in tacrolimus, prednisone and mycophenolate mofetil for immunosuppressive purposes. Patient experienced progressive renal function impairment after 3 months of transplantation. Graft biopsy was performed showing a preserved mesangial matrix and normal cellular glomeruli, but interstitium infiltrated by metastatic adenocarcinoma. Immunohistochemical profile was identical to case $A$ and again serum markers were normal. Despite extensive investigation, no primary tumor was found. PET-CT showed no evidence of metastatic disease elsewhere. Patient was also treated by transplantectomy, without complications and had her immunosuppressive therapy stopped. At follow-up 13 months after transplantectomy, she is well, with no signs of metastatic cancer.
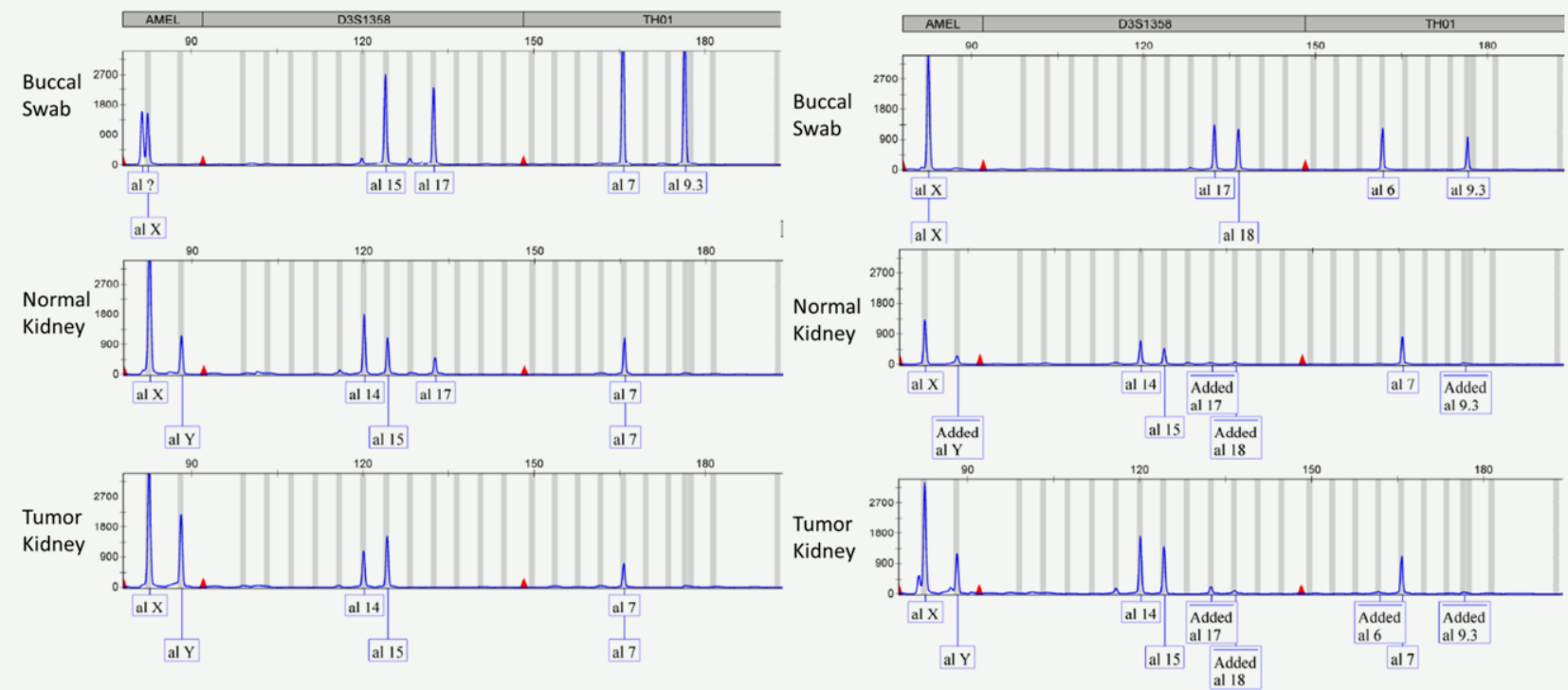

Figure 2. Representative electropherograms from patients $A$ and $B$ amplified with the PowerPlex® ESX 17 System.

The electropherograms show the peaks of fluorescein-labeled loci: Amelogenin, D3S1358, and TH01. Patient A: Buccal Swabs indicate the presence of Amelogenin $X$-specific band. Normal and Tumor kidney present Amelogenin $X$ and $Y$-specific bands. Kidney tissues present extra alleles in loci D3S1358 when compared to the buccal swab. Patient B: Similar to Patient A, buccal Swabs indicate the presence of Amelogenin X-specific band while Normal and Tumor kidney tissues present Amelogenin $X$ and $Y$-specific bands. Both kidneys present extra alleles in loci
D3S1358 and TH01 when compared to the buccal swab

\section{Donor informations}

Both patients received their grafts from the same cadaver donor, a 55 years-old male with no history of chronic disease or cancer. He had normal renal function, serum creatinine of $0.7 \mathrm{mg} / \mathrm{DL}$ and BUN of 14.91 $\mathrm{mg} / \mathrm{dL}$. Brain death occurred after a sub-arachnoid 
hemorrhage. After post transplantation graft failure, cross match testing was performed and was negative in both receptors.

\section{Molecular analisys}

Molecular analysis of DNA samples from the explanted material, the metastasis biopsies and patient's germ line were compared. Four formalin-fixed paraffin-embedded (FFPE) tissue samples from normal and tumor areas within the kidney from Patient $A$ and Patient B were subjected to DNA typing analysis. Buccal swabs collected from each patient were also analyzed. FFPE tissues were micro dissected to enrich for normal and tumor cells. DNA from micro dissected cells was extracted using QIAamp DNA Micro Kit (Qiagen, Hilden, Germany). DNA from buccal swabs was extracted using the QIAamp DNA Mini Kit (Qiagen, Hilden, Germany) following the manufacturer instructions. Purified DNAs were quantified using the Qubit ${ }^{\circledR}$ dsDNA HS Assay Kit (Invitrogen ${ }^{\text {TM }}$ ) and the Qubit ${ }^{\circledR}$ 2.0 Fluorometer (Invitrogen ${ }^{\mathrm{TM}}$ ). DNA content was also measured in a real-time polimerase chain reaction (PCR) using the Plexor ${ }^{\circledR}$ HY System (Promega) according to the manufacturer's instructions. All
DNA samples were investigated using the commercially available PCR multiplex-kit Powerplex ${ }^{\circledR}$ ESX 17 (Promega). The PowerPlex ${ }^{\circledR}$ ESX 17 System is used for human identification investigating both larger and smaller fragments that aid to improve allelic recovery from degraded or challenging samples such as FFPE tissue. Smaller fragments are represented by mini and midi short tandem repeat analysis (STR) which have less than $200 \mathrm{bp}$ in lengh. This system allows co-amplification and five-color fluorescent detection of seventeen loci (sixteen STR loci and Amelogenin). The STR loci include mini-STRs (D2S441, D10S1248 and D22S1045 that), midi-STRs (D1S1656 and D12S391), and larger STRs (D18S51, D21S11, TH01, D3S1358, D16S539, D2S1338, FGA, D8S1179, VWA, SE33, and D19S433). Amelogenin locus displays an $87 \mathrm{bp}, \mathrm{X}$-specific peak and a $93 \mathrm{bp}$, Y-specific peak, allowing for gender identification. Purified DNAs (0.5 ng to $2 \mathrm{ng}$ ) were used as template for DNA amplification following the manufacturer's instructions. Fragment analyses were performed on an ABI 3500 Genetic Analyzer (Applied Biosystems) and analyzed using the GeneMapper ${ }^{\circledR}$ ID Software v5 with the bin set provided by the manufacturer (www.promega. com). Forensic statistic parameters were not applied for analysis.

\section{RESULTS}

The concentration of total human autosomal DNA [Auto] and human male DNA [Y] were measured using the Plexor ${ }^{\circledR}$ HY System (Promega). This measure was used to determine DNA concentration and also to investigate if the sample contains male or female DNA. The [Auto]/[Y] values were equal to 4.4 and 49.4 (Tumor and Normal Kidney from Patient A), 5.0 and 35.8 (Tumor and Normal Kidney from Patient B). Values in the range of 0.4 to 2 are commonly observed in single source male samples. Therefore, the values observed in the kidney samples suggest a mixture of male and female DNA. Moreover, the lower ratios observed in tumor kidney samples (4.4 and 5.0) when compared to normal tissue (49.4 and 35.8 ) suggest higher representation of male DNA in tumor samples.

Profiles obtained for FFPE kidney samples were generally incomplete, with only small fragments less than 200 bp being ampli-fed (Amelogenina, D3S1358,
TH01, D10S1248, D1S1656, D22D1045, vWA, D2S441, and D12S391). Profiles obtained from buccal swabs were complete and demonstrate distinct profiles for Patient A and B. The alleles detected in each sample are summarized in table 1. Gender analysis based on the Amelogenin locus was successfully analyzed on all samples.

The Amelogenin X-specific peaks were observed only in buccal swabs thus indicating female profiles. On the other hand, both Amelogenin X and Y-specific peaks were detected in all four kidney samples supporting the presence of male derived DNA (Table 1 and Figure 1) or a mixture of male and female DNA. The STRs detected in FFPE samples presented a mixed pattern of alleles (Table 1 and Figure 1) suggesting the mixture of DNA from two individuals which is this case, could be derived from the female recipient and the male donor of the Kidney. Interestingly, alleles depicted in gray in 
kidney tissue only (Table 1 ) are similar between Patient $A$ and Patient $B$ suggesting that the DNA could be from the same individual, which is in this case, the individual who donated the organs.
In conclusion, the Amelogenin fragments and the STR profile detected in the kidneys suggest a mix of DNA from the male donor's organ and the female recipient.

Table 1. Locus-Specific Information from patients A and B amplified with the PowerPlex ${ }^{\circ}$ ESX 17 System

\section{Patient A}

\begin{tabular}{|c|c|c|c|c|c|c|c|c|c|c|}
\hline \multirow{2}{*}{$\begin{array}{l}\text { Marker/ } \\
\text { STR }\end{array}$} & \multicolumn{2}{|c|}{ Buccal swab } & \multicolumn{4}{|c|}{ Normal kidney tissue } & \multicolumn{4}{|c|}{ Tumor kidney tissue } \\
\hline & alelle 1 & alelle 2 & alelle 1 & alelle 2 & alelle 3 & alelle 4 & alelle 1 & alelle 2 & alelle 3 & alelle 4 \\
\hline & $x$ & $x$ & $x$ & $x$ & $x$ & $\mathrm{Y}$ & $x$ & $x$ & $x$ & $\mathrm{Y}$ \\
\hline D3S1358 & 15 & 17 & 15 & 17 & 14 & $?$ & 15 & $?$ & 14 & $?$ \\
\hline TH01 & 7 & 9.3 & 7 & $?$ & 7 & $?$ & 7 & $?$ & 7 & $?$ \\
\hline D21s11 & 31 & 32.2 & 31 & $?$ & 30 & $?$ & $?$ & $?$ & 30 & $?$ \\
\hline D18S51 & 16 & 19 & $?$ & 19 & $?$ & $?$ & $?$ & $?$ & 0 & 0 \\
\hline D10S1248 & 15 & 17 & 15 & 17 & 12 & 14 & $?$ & $?$ & 12 & 14 \\
\hline D1S1656 & 17.3 & 18.3 & 17.3 & 18.3 & 11 & 15 & $?$ & $?$ & 11 & 15 \\
\hline $\mathrm{D} 2 \mathrm{~S} 1338$ & 16 & 22 & 16 & $?$ & $?$ & $?$ & 16 & $?$ & $?$ & $?$ \\
\hline D16S539 & 10 & 11 & 10 & $?$ & 13 & $?$ & $?$ & $?$ & $?$ & $?$ \\
\hline D22D1045 & 15 & 15 & 15 & 15 & 16 & 16 & 15 & 15 & 16 & 16 \\
\hline vWA & 16 & 18 & 16 & 18 & 17 & 20 & 16 & $?$ & 17 & 20 \\
\hline d8s1179 & 10 & 15 & 10 & $?$ & 8 & $?$ & 10 & $?$ & 8 & $?$ \\
\hline FGA & 21 & 23 & 21 & 23 & $?$ & $?$ & $?$ & $?$ & $?$ & $?$ \\
\hline D2S441 & 11 & 11 & 11 & 11 & 10 & $?$ & 11 & 11 & 10 & $?$ \\
\hline D12S391 & 20 & 21 & 20 & 21 & $?$ & 24 & 21 & 11 & $?$ & 24 \\
\hline D19S433 & 15 & 17 & 15 & $?$ & 11 & $?$ & $?$ & $?$ & 11 & $?$ \\
\hline SE33 & 15 & 19 & 15 & $?$ & 26.2 & $?$ & $?$ & $?$ & $?$ & $?$ \\
\hline
\end{tabular}

Patient B

\begin{tabular}{|c|c|c|c|c|c|c|c|c|c|c|}
\hline \multirow{2}{*}{$\begin{array}{l}\text { Marker/ } \\
\text { STR }\end{array}$} & \multicolumn{2}{|c|}{ Buccal swab } & \multicolumn{4}{|c|}{ Normal kidney tissue } & \multicolumn{4}{|c|}{ Tumor kidney tissue } \\
\hline & alelle 1 & alelle 2 & alelle 1 & alelle 2 & alelle 3 & alelle 4 & alelle 1 & alelle 2 & alelle 3 & alelle 4 \\
\hline & $x$ & $x$ & $x$ & $x$ & $x$ & Y & $x$ & $x$ & $x$ & Y \\
\hline D3S1358 & 17.3 & 18 & 17 & 18 & 14 & 15 & 17 & 18 & 14 & 15 \\
\hline TH01 & 6 & 9.3 & $?$ & 9.3 & 7 & $?$ & 6 & 9.3 & 7 & $?$ \\
\hline D21s11 & 29 & 30 & $?$ & 30 & $?$ & $?$ & $?$ & 30 & $?$ & $?$ \\
\hline D18S51 & 14 & 17 & $?$ & $?$ & 13 & $?$ & $?$ & $?$ & $?$ & $?$ \\
\hline D10S1248 & 13 & 17 & $?$ & $?$ & 12 & 14 & 13 & $?$ & 12 & 14 \\
\hline D1S1656 & 13 & 17.3 & $?$ & $?$ & 11 & 15 & $?$ & $?$ & 11 & 15 \\
\hline D2S1338 & 23 & 25 & $?$ & $?$ & $?$ & $?$ & $?$ & $?$ & 16 & $?$ \\
\hline D16S539 & 9 & 11 & $?$ & $?$ & $?$ & $?$ & $?$ & $?$ & $?$ & $?$ \\
\hline D22D1045 & 11 & 15 & 11 & 15 & 16 & 16 & 11 & 15 & 16 & 16 \\
\hline vWA & 15 & 16 & $?$ & $?$ & $17-18$ & 20 & 15 & $?$ & 17 & 20 \\
\hline d8s1179 & 10 & 13 & 10 & $?$ & 8 & $?$ & 10 & $?$ & 8 & $?$ \\
\hline FGA & 23 & 24 & $?$ & $?$ & 0 & 0 & $?$ & $?$ & $?$ & $?$ \\
\hline D2S441 & 11 & 14 & 11 & $?$ & 10 & $?$ & 11 & 14 & 10 & $?$ \\
\hline D12S391 & 18 & 19 & $?$ & $?$ & 21 & 24 & 18 & $?$ & 21 & 24 \\
\hline D19S433 & 12 & 13 & 15 & $?$ & 0 & 0 & $?$ & 13 & 11 & $?$ \\
\hline SE33 & 28.2 & 29.2 & $?$ & $?$ & $?$ & $?$ & $?$ & $?$ & $?$ & $?$ \\
\hline
\end{tabular}


The alleles detected for each locus are presented. Buccal swab profiles are distinct for Patient A and Patient B. Alleles detected in common between buccal swab and kidney tissue were displayed as Allele 1 and 2. Alleles detected only kidney tissues are displayed in Allele 3 and 4 (highlighted in gray). The Nor- mal and tumor kidney profiles are mostly mixed with the alleles detected in buccal swab. Alleles in gray are similar between Patient A and Patient B kidney tissue but were not detected in buccal swabs suggesting a profile from the same individual that donated the organs.

\section{DISCUSSION}

Tumor transmission by kidney transplantation is an extremely rare situation with the incidence of approximately two cases per 10.000 organ transplant recipients. ${ }^{(3)}$ The most common type of cancer transmitted is renal cell carcinoma, followed by lymphoma, melanoma and lung cancer. Lung cancer and melanoma transmissions have the worst prognosis, with less than $50 \%$ of recipients alive after 24 months from transplantation. ${ }^{(3)}$

With a lack of strong evidence, the approach of immunosuppressive withdraw and transplantectomy seems to be the most appropriated treatment, although the use of chemotherapy and radiotherapy has already been considered. ${ }^{(3,4)}$ Most recently, the role of mTOR inhibitors, sirolimus and everolimus, in patients with post-transplantation malignancy is being evaluated, as these drugs present immunosuppressive and anti-tumoral activity. ${ }^{(5)}$

Our patients obtained complete anti-tumoral response with withdrawal of immunosuppressive regimen, after explantation. Metastatic disease outside the transplanted kidney, like the ones detected by PET-CT in patient A, completed disappeared showing that properly active cellular immunity can eliminate allogeneic cells even when they are transformed. The same is certainly not true when one considered the immune surveillance for controlling tumorigenicity. Although epidemiologic studies of immuno- suppressed transplantation patients show significant increase in the incidence of some malignancies (commonly viral induced), the increase in others (like gastrointestinal tumors) are mostly nonsignificant.

The presence of genetic material of the recipient within the transplanted kidney, explanted still during the immunosuppressive treatment (as showed in table 1) corresponds to leukocytes, mainly lymphocytes activated, and may reflect the latent and clinically ineffective immune response against the tumor and the graft.

A curious finding in Case $A$ is the location of the lymph node metastasis. The onset of the left supraclavicular lymph node, classically known as Virchow's node, is a typical finding of malignancies of the upper gastrointestinal tract. It's believed that this spread pattern occurs exclusively by anatomical thoracic and abdominal particularities, concerning to regional lymph nodes drainage. Patient $\mathrm{A}$ had a unique metastasis presenting as a Virchow's node but had her gastrointestinal tumor cells transplanted in the pelvic cavity. The reason why a tumor located in a place which has the anatomy and lymphatic drainage totally different would migrate to this place remains unclear. A reasonable hypothesis for this would be that specific microenvironment provided a favorable location for the gastrointestinal malignant cell development.

\section{CONCLUSION}

In conclusion, we report an extremely rare situation in which a malignancy of gastrointestinal origin was transmitted by kidney transplantation to two differ- ent recipients. Both patients were treated without cytotoxic drugs and are now without any kind disease evidence. 


\section{Author's contribution}

Couldry R. and Meireles SI. carried out the molecular genetic studies, immunoassays, and participated in the sequence alignment and drafted the manuscript. David Neto E. carried out pathological analysis. Exman P. and Sabbaga J. conceived of the study, and participated in its design and coordination and helped to draft and revise the manuscript. All authors read and approved the final manuscript.

\section{REFERENCES}

1. Gandhi MJ, Strong DM. Donor derived malignancy following transplantation: a review. Cell Tissue Bank. 2007;8(4):26786. Review.

2. Ajithkumar TV, Parkinson CA, Butler A, Hatcher HM. Management of solid tumours in organ-transplant recipients. Lancet Oncol. 2007;8(10):921-32. Review.

3. Xiao D, Craig JC, Chapman JR, Dominguez-Gil B, Tong A, Wong G. Donor câncer transmission in kidney transplantation: a systematic review. Am J Transplant. 2013;13(10):264552. Review.

4. Chapman JR, Webster AC, Wong G. Cancer in the transplant recipient. Cold Spring Harb Perspect Med. 2013;3(7). pii: a015677. Review.

5. Bunnapradist S, Vincenti F. Transplantation: To convert or not to convert:lessons from the CONVERT trial. Nat Rev Nephrol. 2009;5(7):371-3. 